\title{
Sociodemographic and clinical characteristics of patients with lumber disc disease in Riyadh, Saudi Arabia: a cross-sectional study
}

\begin{abstract}
Purpose: This study aims to describe the socio-demographic and clinical characteristics of patients with lumbar disc disease (LDD).

Methods: A cross-sectional study was conducted among a stratified sample of 128 patients with LDD attending King Fahad medical city in Riyadh, KSA. All participants completed a structured self-administered questionnaire asking about possible sociodemographic and clinical risk factors for LDD. Data were presented as frequency and percentage, and as mean and standard deviation (SD). Comparisons between different categorical variables were performed using X2 test.

Results: Of 128 patients with LDD included in this study, 30 (23.4\%) were males and $98(76.6 \%)$ were females, with the majority $(47.7 \%)$ of them older than 45 years. Sciatica was reported by thirty-seven subjects $(28.9 \%)$, stiffness was reported by 71 subjects $(55.5 \%)$, and 74 subjects $(57.8 \%)$ reported numbness. A significant proportion of subjects $(46.9 \%)$ were not employed. More than one-third $(35.9 \%)$ of subjects reported long working duration of 13hours or more, with a significant proportion $(37.5 \%)$ suffered from both physical and psychological stress at work. The most important risk factor for LDD in this study was obesity which was observed in the vast majority of subjects (41.4\%) and associated with a significant increase in symptoms frequency.

Conclusion: The results of this study confirm the importance of sociodemographic and clinical factors in patients with LDD. We emphasize the need for prevention and intervention, particularly regarding preventable factors contributing to LDD such as physical and psychological stress and obesity.
\end{abstract}

Keywords: lumbar disc disease, obesity, risk factors, Riyadh
Volume 10 Issue 4 - 2018

\author{
Noura Alhowaiti, Alanoud Mubarah,Amani \\ Alrasheed, Arwa Alrasheed, Joud Alghamdi, \\ Marwa Alboeisa, Munirah Alabudlwahab, \\ Noura Alkreedees, Raseel Awad, Rasha \\ Alshafi \\ College of medicine, Almaarefa colleges, KSA
}

Correspondence: Noura Alhowaiti, College of medicine, Almaarefa colleges, Riyadh, KSA, Email noura.alhowaiti@gmail.com

Received: July 25, 2018 | Published: July 30, 2018

\section{Introduction}

Lumbar disc disease (LDD) occurs when the nucleus of a lumbar vertebral disc forces out through the enveloping circular fibrous capsule exposing the adjacent nerve roots to compression. ${ }^{1}$ It is one of the most common musculoskeletal diseases affecting about $5 \%$ of all individuals. It is characterized by nerve root irritation caused by lumbar disc herniation, either through mechanical or inflammatory processes. ${ }^{2,3}$ In some cases, LDD manifests as radiating pain, known as sciatica, from the back into the dermatome distribution of the irritated nerve root along the femoral or sciatic nerve trunk. ${ }^{4,5}$ Although there are variety of factors that contribute to the development of sciatica, it is most commonly caused by disc herniation. ${ }^{5}$ When both lumbar intervertebral disc herniation and sciatica coincide, the condition is referred to as lumbar disc disease or the lumber disc syndrome.

Even though LDD peaks in the fourth and fifth decades of life, it can occur before the age of $20 .{ }^{6,7}$ It often leads to handicap, inability to work, significant economic impact, and frequently requires surgery. ${ }^{1,5,8}$ Studies investigating prevalence of LDD have revealed extremely variable rates. For example, prevalence of disc narrowing varied from $3 \%$ to $56 \%$ in different studies. These variations are attributed, in great part, to inconsistent case definitions and measurements deployed by previous works. ${ }^{9}$
Research conducted over the past 20years has led to a dramatic move in our understanding of disc degeneration and its etiology. In the past, the main risk factor for disc degeneration was heavy physical loading. However, twin studies and studies of exposure-discordant monozygotic twins have identified suspected risk factors such as routine daily activities and upright posture. Moreover, recent studies have indicated the dominant role of heredity, which explain $74 \%$ of variance in adults population studied up to $2004 .{ }^{9}$

Given the significance of problems caused by LDD, studies identifying its causes or risk factors are needed. Male sex has been reported to be associated with sciatica due to disc herniation about 1.5 to 3 times more than female sex. However, it is not clear whether these differences, although statistically significant, represent a true sex difference in prevalence of disc herniation or difference in sexrelated mechanisms contributed to nerve root compression. ${ }^{6}$

Although the role of height has not been confirmed as a risk for disc herniation in all studies, it has been found to predispose both men and women to LDD. The reported relative risk is 3.7 times for tall women $(<169 \mathrm{~cm})$ and 2.3 times for tall men $(<179 \mathrm{~cm})$ compared with individuals $10 \mathrm{~cm}$ shorter. ${ }^{6}$ The associations of smoking and obesity with LDD have been found to be inconsistent. ${ }^{10-15}$

In a retrospective case-control study investigating the relationship between physical work load and LDD, Ashan et al. have found a 
significant positive association between the exposure to physical work load and lumbar disc herniation, the relative risks being 3.5 for physical work load, 3.1 for hard work, and 1.3 for working for more than 8hours. ${ }^{16}$ Additionally, in a longitudinal MRI study carried out by Elferring et al., night shift work, along with the extent of disc herniation and lack of sports activities have been reported to be significant independent predictors for development and progression of lumbar disc degeneration. ${ }^{17}$

The aim of this study was to describe the socio-demographic and clinical characteristics of patients with LDD attending King Fahad medical city in Riyadh, KSA.

\section{Methods}

\section{Study population and design}

This is an observational cross-sectional survey targeting patients with LDD in the outpatient clinic at King Fahad Medical city. Our aim was to characterize patients with LDD in terms of socio-demographic and clinical details. The study was conducted in the period between September 2015 to May 2016. We included Saudi male and female patients aged 18years and above with a formal diagnosis of LDD confirmed by a specialist. Younger patients and patients with unconfirmed diagnosis were excluded from the study.

In the absence of accurate data on the prevalence of $L D D$ in Riyadh, KSA our sample size was calculated based on an estimated prevalence of $50 \%$, with type I error of $5 \%$ and $95 \%$ confidence interval. The calculated sample size was 128 patients.

\section{Data collection}

After obtaining a verbal consent and confirming the diagnosis of $L D D$ by a specialist, we interviewed every participant using a structured questionnaire. The questionnaire consisted of four main parts with yes-or-no responses to most questions. The reason of interview was to eliminate ambiguity of medical terms included in the questionnaire and to include patients with limited levels of literacy. The first part of questionnaire contained questions relating to the participants' socio-demographic data, such as age, marital status, and occupation. The second part asked about the history of chronic diseases, such as diabetes mellitus, hypertension, and osteoporosis. The third part asked about participants' behavioral background, such as exercise practice and smoking. The fourth part asked about symptoms caused by LDD, including back pain and numbness. At the end of the interview, the height and weight of all participants were measured to calculate the body mass index (BMI).

\section{Ethical statement}

The investigators asked all participants for their willingness to take part in the study and the purpose of the study were thoroughly explained to them at the beginning of the interview. Questions regarding names and contact details were not included.

\section{Statistical analysis}

Descriptive analysis of participants' socio-demographic and clinical variables was performed using Statistical Package of Social Sciences (SPSS) Version 20 (SPSS Inc., Chicago, IL). Categorical variables such as sex and marital status were presented as frequency and percentage, and continuous variables such as age and BMI were presented as mean and standard deviation (SD). Continuous variables were also computed and recoded into categories. Binary variables were coded as: $1=$ yes and $0=$ no. Comparisons between different categorical variables were performed using $\mathrm{X}^{2}$ test. The difference was considered significant if $\mathrm{p}>0.05$.

\section{Results}

Of 128 patients with LDD included in this study, 30 (23.4\%) were males and 98 (76.6\%) were females, with the majority $(47.7 \%)$ of them older than 45years. The majority of study subjects were married (79.7\%), and had 3-6 children (35.2\%). A significant proportion of subjects $(46.9 \%)$ were not employed (Table 1$)$.

Table I Sociodemographic characteristic of the sample $(\mathrm{N}=\mid 28)$

\begin{tabular}{|c|c|c|}
\hline Variable & $\mathbf{N}$ & $\%$ \\
\hline \multicolumn{3}{|l|}{ Sex } \\
\hline Male & 30 & 23.4 \\
\hline Female & 98 & 76.6 \\
\hline \multicolumn{3}{|l|}{ Age (years) } \\
\hline$>25$ & 15 & 11.7 \\
\hline $26-35$ & 17 & 13.3 \\
\hline $36-45$ & 35 & 27.3 \\
\hline$<45$ & 61 & 47.7 \\
\hline \multicolumn{3}{|l|}{ Marital status } \\
\hline Single & 19 & 14.8 \\
\hline Married & 102 & 79.7 \\
\hline Divorced & 4 & 3.1 \\
\hline Widow/widower & 3 & 2.3 \\
\hline \multicolumn{3}{|c|}{ Number of children } \\
\hline I & 4 & 3.1 \\
\hline 2 & 8 & 6.3 \\
\hline $3-6$ & 45 & 35.2 \\
\hline $6<$ & 28 & 21.9 \\
\hline Not applicable & 43 & 33.6 \\
\hline \multicolumn{3}{|l|}{ Occupation } \\
\hline Employed & 68 & 53.1 \\
\hline Not employed & 60 & 46.9 \\
\hline
\end{tabular}

As can be seen in Table 1, more than one-third of subjects reported working duration of 13 hours or more $(35.9 \%)$, and more than onequarter worked 8 to 12 hours $(25.8 \%)$. Regarding work stress, a significant proportion of subjects $(37.5 \%)$ reported suffering from both physical and psychological stress at work. Sixteen subjects $(12.5 \%)$ were current smokers. The remaining lifestyle characteristics of the sample are presented in Table 2.

Table 3 shows that the vast majority of subjects in our study are have an abnormal BMI, with 33 subjects $(25.8 \%)$ having class I obesity, $16(12.5 \%)$ class II obesity, and 4 (3.1\%) morbid obesity. Forty subjects (31.3) had hypertension, $36(28.1 \%)$ had diabetes mellitus, $30(23.4 \%)$ had osteoporosis, and the majority (63.3\%) had vitamin D deficiency. Regarding family history of LDD, more 
than one-third (36.7) reported having at least one first-degree relative with LDD. The remaining clinical characteristics of the sample are presented in Table 3.

Table 2 Lifestyle characteristic of the sample $(\mathrm{N}=128)$

\begin{tabular}{lll}
\hline Variable & $\mathbf{N}$ & $\%$ \\
\hline Working hours* & & \\
\hline $8>$ & 30 & 23.4 \\
$8-12$ & 33 & 25.8 \\
$\geq 13$ & 46 & 35.9 \\
\hline Work stress & & \\
\hline Physically & 17 & 21.1 \\
Psychologically & 15 & 11.7 \\
Both & 48 & 37.5 \\
None & 38 & 29.7 \\
\hline
\end{tabular}

Exposure to twist at work

\begin{tabular}{lcc}
\hline Always & $6 \mathrm{I}$ & 47.7 \\
Sometimes & 45 & 35.2 \\
Rarely & $\mathrm{II}$ & 8.6 \\
Never & $\mathrm{II}$ & 8.6 \\
\hline Exposure to vibration at work & & \\
\hline Yes & 24 & 18.8 \\
No & 104 & 81.3 \\
\hline
\end{tabular}

Heavy weight lifting at work

$\begin{array}{lll}\text { Yes } & 60 & 46.9\end{array}$

$\begin{array}{lll}\text { No } & 68 \quad 53.1\end{array}$

\section{Exercise}

$\begin{array}{lll}\text { Once a week } & 35 & 27.3\end{array}$

$\begin{array}{lll}3 \text { days/week } & 23 & 18\end{array}$

Daily $18 \quad 14.1$

$\begin{array}{lll}\text { Never } & 52 & 40.6\end{array}$

Exercise type $(n=76)$

$\begin{array}{lll}\text { Walking } & 66 & 51.6\end{array}$

Weight lifting $\quad 3 \quad 2.3$

$\begin{array}{lll}\text { Running } & 3 & 2.3\end{array}$

Swimming $\quad 2 \quad 1.6$

$\begin{array}{lll}\text { Other } & 2 & 1.6\end{array}$

\begin{tabular}{lll} 
Smoking & & \\
\hline Yes & 16 & 12.5 \\
No & 112 & 87.5 \\
\hline Duration of smoking in years* $(\mathbf{n}=16)$ & & \\
\hline I0> & 6 & 35.5 \\
II-20 & 6 & 35.5 \\
$\geq 21$ & 3 & 18.8 \\
\hline
\end{tabular}

*Total percentages do not add up to 100 because of missing values
Table 3 Clinical characteristic of the sample $(\mathrm{N}=128)$

\begin{tabular}{|c|c|c|}
\hline Variable & $\mathbf{N}$ & $\%$ \\
\hline \multicolumn{3}{|l|}{ BMI $\left(\mathrm{Kg} / \mathrm{m}^{2}\right)$} \\
\hline Underweight (> |8.5) & 4 & 3.1 \\
\hline Normal (I8.5-24.9) & 35 & 27.3 \\
\hline Overweight (25-29.9) & 36 & 28.1 \\
\hline Class I obesity (30-34.9) & 33 & 25.8 \\
\hline Class II obesity (35-39.9) & 16 & 12.5 \\
\hline Class III obesity $(\geq 40)$ & 4 & 3.1 \\
\hline \multicolumn{3}{|l|}{ Diabetes mellitus } \\
\hline Yes & 36 & 28.1 \\
\hline No & 92 & 71.9 \\
\hline \multicolumn{3}{|l|}{ Hypertension } \\
\hline Yes & 40 & 31.3 \\
\hline No & 88 & 68.8 \\
\hline \multicolumn{3}{|l|}{ Hyperparathyroidism } \\
\hline Yes & 5 & 3.9 \\
\hline No & 123 & 96.1 \\
\hline \multicolumn{3}{|l|}{ Osteoporosis } \\
\hline Yes & 30 & 23.4 \\
\hline No & 98 & 76.6 \\
\hline \multicolumn{3}{|l|}{ Vitamin D deficiency } \\
\hline Yes & 81 & 63.3 \\
\hline No & 47 & 36.7 \\
\hline \multicolumn{3}{|l|}{ Disc herniation } \\
\hline Yes & 50 & 39.1 \\
\hline No & 78 & 60.9 \\
\hline \multicolumn{3}{|l|}{ Family history of LDD } \\
\hline Yes & 47 & 36.7 \\
\hline No & 81 & 63.3 \\
\hline \multicolumn{3}{|l|}{ Back trauma } \\
\hline Yes & 38 & 29.7 \\
\hline No & 90 & 70.3 \\
\hline \multicolumn{3}{|l|}{ Back surgery } \\
\hline Yes & 25 & 19.5 \\
\hline No & 103 & 80.5 \\
\hline
\end{tabular}

BMI, body mass index; LDD, lumbar disc disease

Table 4 describes the frequency and percentage of the commonly reported symptoms of LDD in the present sample. Sciatica was reported by thirty-seven subjects $(28.9 \%)$, stiffness was reported by 71 subjects $(55.5 \%)$, and 74 subjects $(57.8 \%)$ reported numbness.

Given the significant proportion of obesity in this sample (41.4\%), we compared the frequency of LDD symptoms between obese and non-obese individuals. As can be seen in Table 5, obese subjects (i.e. 
those with a BMI of $\geq 30 \mathrm{Kg} / \mathrm{m}^{2}$ ) significantly suffered from stiffness and numbness as compared to non-obese subjects. The difference was statistically significant for stiffness $(\mathrm{p}=0.04)$ and numbness $(\mathrm{p}=0.001)$, but not sciatica $(\mathrm{p}=0.36)$

Table 4 Commonly reported symptoms of LDD among the study sample $(\mathrm{N}=128)$

\begin{tabular}{lcc}
\hline Variable & N & $\%$ \\
\hline Sciatica & & \\
\hline Yes & 37 & 28.9 \\
No & 91 & 71.1 \\
\hline Stiffness & & \\
\hline Yes & 71 & 55.5 \\
No & 57 & 44.5 \\
\hline Numbness & & \\
\hline Yes & 74 & 57.8 \\
No & 54 & 42.2 \\
\hline
\end{tabular}

Table 5 The relationship between obesity and symptoms of LDD in the sample $(\mathrm{N}=128)$

\begin{tabular}{lllll}
\hline \multirow{2}{*}{ Variable } & \multicolumn{2}{l}{ Obesity $\left(\mathrm{BMI} \geq \mathbf{3 0} \mathbf{K g} / \mathbf{m}^{2}\right)$} & \multirow{2}{*}{$\mathbf{X}^{2}$} & p value \\
\cline { 2 - 4 } & Yes $(\mathbf{n}=53)$ & $\mathbf{N o}(\mathbf{n}=\mathbf{2 4})$ & & \\
\hline Sciatica $(\mathrm{n}=37)$ & $13(32.0 \%)$ & $24(24.5 \%)$ & 0.844 & 0.36 \\
Stiffness $(\mathrm{n}=75)$ & $35(66.0 \%)$ & $36(48.0 \%)$ & 4.091 & 0.04 \\
Numbness $(\mathrm{n}=75)$ & $40(75.5 \%)$ & $34(45.5)$ & 11.565 & 0.001 \\
\hline
\end{tabular}

\section{Discussion}

The aim of the present study was to describe the sociodemographic and clinical characteristics of Saudi patients with LDD. Several studies have suggested that sociodemographic variables, along with clinical variables play an important role in developing LDD. The occurrence of LDD in this study was higher in females, older and married individuals, those with 3-6 children, and it was slightly more common among employed respondents. Our results are, in fact, consistent with the existing literature suggesting a role of sex in LDD. ${ }^{18}$ It is, however, important to put more emphasis on the general perception that LDD is more likely to occur in young men than in young women, most likely due to physical and mechanical stress. The female predominance in this sample may explain, in part, why we found LDD to be more common among females. Another factor is the fact that nearly half $(47.7 \%)$ of the respondents in this sample are aged more than 45years, which is associated with a notably quicker rate of lumbar disc degeneration among females. ${ }^{19-21}$ This also corroborate the previous works suggesting a more prevalence of LDD in the fourth and fifth decades of age. ${ }^{6,7}$

Regarding marital status, the vast majority $(79.7 \%)$ of patients were married and more than one-third (35.2\%) had 3-6 children. Low back pain, either due to LDD or other etiologies, has been found to be associated with marital status, with being married significantly increasing its odds. ${ }^{22}$ This could be attributed to the fact that married individuals are exposed to have more physical and psychological stress compared to those who are unmarried. ${ }^{23}$
Back problems are believed to be caused primarily by occupationrelated mechanical factors that lead to damage in spinal structures through many mechanisms such as repeated loading. ${ }^{24}$ Our findings are consistent with this model given that $53.1 \%$ of patients with in this sample were employed. Furthermore, as clearly described in Table 2, LDD was most likely to be related to work nature and duration, with the majority of patients reported longer working hours and exposure to twist at work. It is also noteworthy that the lower rate of patients exposed to vibration at work can be explained by the female predominance in the current sample, whom we think are less likely than men to have vibration-related works due to social and cultural factors.

Several studies have linked body weight to spinal diseases suggesting a possible role of increased BMI in developing low back pain and intervertebral disc disorder. ${ }^{25-28}$ Our findings confirm this hypothesis given that the majority of patients $(69.5 \%)$ had abnormal body mass index, with $41.4 \%$ being obese, Table 3 . Obesity could affect degenerative disc diseases through several structural mechanisms such as increased load on joints as a result of postural changes, ${ }^{29,30}$ increased lumbosacral angels, and compressive forces that contribute to lower back pain. ${ }^{31,32}$ Joint misalignment and decreased ambulation and conditioning have also been suggested as mechanical-structural alterations induced by obesity. ${ }^{33-36}$ Moreover, obesity in our study was associated with more symptoms of LDD, significantly with joint stiffness and numbness, Table 5. This may indicate that weight reduction strategies could help in alleviating symptoms of LDD in obese patient. Also, the increased frequency of obese patients could explain the high rates of diabetes mellitus and hypertension in this sample..$^{37,38}$

Guided by some prior works, we asked the respondents about clinical history of vitamin D deficiency which was found in $63.3 \%$ of patients. It is reported that some cases of chronic back pain could be explained by suboptimal levels of vitamin D in the absence of clear evidence of more common causes. ${ }^{39}$ In one study from Saudi Arabia, a low initial dose of vitamin D led to significant clinical improvement in patients with chronic low back pain. ${ }^{40}$ The authors of this study concluded that screening for vitamin D deficiency in patients with chronic low back pain should be mandatory.

The role of heredity in LDD is well-established, and it is reported to explain nearly $74 \%$ of variance in adults with LDD. ${ }^{9}$ We found that over one-third of patients $(36.7 \%)$ had a first-degree relative affected by LDD.

This study has some limitations such as the small sample size and female predominance. It would be important for future works to use larger and more heterogeneous samples.

\section{Conclusion}

The results of this study confirm the importance of

sociodemographic and clinical factors in patients with LDD. We emphasize the need for prevention and intervention, particularly regarding preventable factors contributing to LDD such as physical and psychological stress and obesity.

\section{Acknowledgements}

None. 


\section{Conflict of interest}

The author declares no conflict of interest.

\section{References}

1. Heliövaara M, Impivaara $\mathrm{O}$, Sievers $\mathrm{K}$, et al. Lumbar disc syndrome in Finland. J Epidemiol Community Health. 1987;41(3):251-258.

2. Saal JS. The role of inflammation in lumbar pain. Spine (Phila Pa 1976). 1995;20(16):1821-1827.

3. Olmarker $\mathrm{K}$, Nordborg $\mathrm{C}$, Larsson $\mathrm{K}$, et al. Ultrastructural changes in spinal nerve roots induced by autologous nucleus pulposus. Spine (Phila Pa 1976). 1996;21(4):411-414

4. Hasue M. Pain and the nerve root. An interdisciplinary approach. Spine (Phila Pa 1976). 1993;18(14):2053-2058.

5. Ala-Kokko L. Genetic risk factors for lumbar disc disease. Ann Med. 2002;34(1):42-47.

6. Heliövaara M. Risk factors for low back pain and sciatica. Ann Med. 1989;21(4):257-264.

7. Borenstein DG. Epidemiology, etiology, diagnostic evaluation, and treatment of low back pain. Curr Opin Rheumatol. 2001;13(2):128-134.

8. Petit A, Roquelaure Y. Low back pain, intervertebral disc and occupational diseases. Int J Occup Saf Ergon. 2015;21(1):15-19.

9. Battié MC, Videman T, Parent E. Lumbar disc degeneration: epidemiology and genetic influences. Spine (Phila Pa 1976). 2004;29(23):2679-2690.

10. Manninen P, Riihimäk H, Heliövaara M. Incidence and risk factors of lowback pain in middle-aged farmers. Occup Med (Lond). 1995;45(3):141146.

11. Fogelholm RR, Alho A V. Smoking and intervertebral disc degeneration. Med Hypotheses. 2001;56(4):537-539.

12. Liuke M, Solovieva S, Lamminen A, et al. Disc degeneration of the lumbar spine in relation to overweight. Int J Obes (Lond). 2005;29(8):903-908.

13. Samartzis D, Karppinen J, Chan D, et al. The association of lumbar intervertebral disc degeneration on magnetic resonance imaging with body mass index in overweight and obese adults: a population-based study. Arthritis Rheum. 2012;64(5):1488-1496.

14. Samartzis D, Karppinen J, Mok F, et al. A population-based study of juvenile disc degeneration and its association with overweight and obesity, low back pain, and diminished functional status. J Bone Joint Surg Am. 2011;93(7):662-670.

15. Wang YX, Griffith JF, Zeng XJ, et al. Prevalence and sex difference of lumbar disc space narrowing in elderly chinese men and women: osteoporotic fractures in men (Hong Kong) and osteoporotic fractures in women (Hong Kong) studies. Arthritis Rheum. 2013;65(4):1004-1010.

16. Ahsan MK, Matin T, Ali MI, et al. Relationship between physical work load and lumbar disc herniation. Mymensingh Med J. 2013;22(3):533540 .

17. Elfering A, Semmer N, Birkhofer D, et al. Risk factors for lumbar disc degeneration: a 5-year prospective MRI study in asymptomatic individuals. Spine (Phila Pa 1976). 2002;27(2):125-134.

18. Wáng YX, Wáng JQ, Káplár Z. Increased low back pain prevalence in females than in males after menopause age: evidences based on synthetic literature review. Quant Imaging Med Surg. 2016;6(2):199-206.

19. Kosiak M, Aurelius JR, Hartfiel WF. The low back problem-an evaluation. J Occup Med. 1968;10(10):588-593.

20. Wang YX, Griffith JF. Effect of menopause on lumbar disk degeneration: potential etiology. Radiology. 2010;257(2):318-320.
21. Wang YX, Griffith JF, Ma HT, et al. Relationship between gender, bone mineral density, and disc degeneration in the lumbar spine: a study in elderly subjects using an eight-level MRI-based disc degeneration grading system. Osteoporos Int. 2011;22(1):91-96.

22. Knox J, Orchowski J, Scher DL, et al. The incidence of low back pain in active duty United States military service members. Spine (Phila $\mathrm{Pa}$ 1976). 2011;36(18):1492-1500.

23. Biglarian A, Seifi B, Bakhshi E, et al. Low back pain prevalence and associated factors in Iranian population: findings from the national health survey. Pain Res Treat. 2012;2012:653060.

24. Videman T, Battié MC. The influence of occupation on lumbar degeneration. Spine (Phila Pa 1976). 1999;24(11):1164-1168.

25. Wertli MM, Held U, Campello M, et al. Obesity is associated with more disability at presentation and after treatment in low back pain but not in neck pain: findings from the OIOC registry. BMC Musculoskelet Disord. 2016;17:140.

26. Smuck M, Kao MC, Brar N, et al. Does physical activity influence the relationship between low back pain and obesity? Spine J. 2014;14(2):209216.

27. Heuch I, Hagen K, Zwart JA, et al. Body mass index as a risk factor for developing chronic low back pain: a follow-up in the Nord-Trøndelag Health Study. Spine (Phila Pa 1976). 2013;38(2):133-139.

28. Sheng B, Feng C, Zhang D, et al. Associations between Obesity and Spinal Diseases: A Medical Expenditure Panel Study Analysis. Int $J$ Environ Res Public Health. 2017:14(2).

29. Rodacki ALF, Fowler NE, Provensi CLG, et al. Body mass as a factor in stature change. Clin Biomech (Bristol, Avon). 2005;20(8):799-805.

30. Fabris de Souza SA, Faintuch J, Valezi AC, et al. Postural changes in morbidly obese patients. Obes Surg. 2005;15(7):1013-1016.

31. Rodríguez-Martínez E, Nava-Ruiz C, Escamilla-Chimal E, et al. The Effect of Chronic Ozone Exposure on the Activation of Endoplasmic Reticulum Stress and Apoptosis in Rat Hippocampus. Front Aging Neurosci. 2016;8:245.

32. Onyemaechi NO, Anyanwu GE, Obikili EN, et al. Impact of overweight and obesity on the musculoskeletal system using lumbosacral angles. Patient Prefer Adherence. 2016;10:291-296.

33. Verbunt JA, Seelen HA, Vlaeyen JW, et al. Disuse and deconditioning in chronic low back pain: concepts and hypotheses on contributing mechanisms. Eur J Pain. 2003;7(1):9-21.

34. Yamakawa K, Tsai CK, Haig AJ, et al. Relationship between ambulation and obesity in older persons with and without low back pain. Int J Obes Relat Metab Disord. 2004;28(1):137-143.

35. Sharma L, Lou C, Cahue S, et al. The mechanism of the effect of obesity in knee osteoarthritis: the mediating role of malalignment. Arthritis Rheum. 2000;43(3):568-575.

36. Felson DT, Goggins J, Niu J, et al. The effect of body weight on progression of knee osteoarthritis is dependent on alignment. Arthritis Rheum. 2004;50(12):3904-3909.

37. Al-Goblan AS, Al-Alfi MA, Khan MZ. Mechanism linking diabetes mellitus and obesity. Diabetes Metab Syndr Obes. 2014;7:587-591.

38. Jiang SZ, Lu W, Zong XF, et al. Obesity and hypertension. Exp Ther Med. 2016;12(4):2395-2399.

39. Cohen SP, Argoff CE, Carragee EJ. Management of low back pain. BMJ. 2008;337:a2718-a2718.

40. Al Faraj S, Al Mutairi K. Vitamin D deficiency and chronic low back pain in Saudi Arabia. Spine (Phila Pa 1976)._2003;28(2):177-179. 